\title{
As relações informacionais na sociedade reflexiva de Giddens
}

\section{Lígia Maria Moreira Dumont}

Professora adjunta da Escola de Ciência da Informação da UFMG. D outora em Comunicação e Cultura.

E-mail: dumont@eci.ufmg.br

\section{Roberto Luís C apuruço $\mathbf{G}$ attoni}

M estre em ciência da informação pela Escola de Ciência da Informação da U FM G. Bacharel em ciência da computação. E-mail: rgattoni@inet.com.br

\section{Resumo}

São revistos postulados e argumentações sobre a modernidade reflexiva de Anthony Giddens, pontuados com exemplos de ações sociais e de subjetividade exercidos na contemporaneidade pelo sujeito e pela coletividade no seu cotidiano. Entre essas ações, é dado especial enfoque à relação homem-computador. Destaca-se ainda que o principal papel da linha de pesquisa informação e sociedade é analisar as teorias sociais, para verificar a possibilidade de sintonia com os estudos das práticas informacionais em contextos específicos.

\section{Palavras-chave}

Giddens - sociedade de riscos; Informação e sociedade; Giddens - reflexividade; Interação homem-máquina.

\section{Informational relations in Giddens' reflexive society}

\begin{abstract}
Within the research area line 'Information and Society', one can point out arguments developed by the contemporary author Anthony Giddens. The debate is enlightened on by examples of social action and subjectivity, currently played actors and communities in their day-to-day interaction. Men-machine relations receive special attention. Giddens explains also other types of actions nowadays, based on fundamentalism. He explains that these actions are strong reactions of some religions that felt insecure due to the break of traditions and the news brought by the cosmopolitan world.
\end{abstract}

\section{Keywords}

Giddens - venture society; Information and society; Giddens - reflexivity; Man-machine interaction.
No início da década de 90, Giddens (1991) publicou a obra que iria lançar mais polêmica à já controvertida questão dos intelectuais contemporâneos: se a humanidade estaria, ou não, ingressando em nova ordem social, então cunhada de pós-modernidade, ou pósindustrial. Causou certo estranhamento ao defender a tese de a civilização na realidade estar vivenciando a era da "alta-modernidade" - debate que se vem prolongando até os dias atuais. Contudo, os conceitos estabelecidos pelo autor sobre sistemas abstratos*, mecanismos de confiança (o significado desta característica será detalhado adiante) e de desencaixe e reencaixe** foram, sem dúvida, enfeixamentos teóricos inovadores no auxílio ao entendimento das transformações sociais - ou da intimidade, como especifica o autor - da época atual, denominada modernidade ref lexiva***.

A análise das teorias sociais mostra-se cada vez mais necessária, pois sob a ótica do autor verificam-se também as conseqüências porventura ocorridas na forma de buscar, usar e transmitir informações na sociedade contemporânea. A linha de pesquisa "Informação e Sociedade" vem tradicionalmente preocupando-se em estudar os processos sociais e culturais de grupos de atores na sociedade, visando a verificar como estes se traduzem

\footnotetext{
* Giddens (1991) denomina sistemas abstratos o "conjunto de sistemas peritos e de fichas simbólicas" (p.84) definidos pelo autor como "mecanismos de desencaixe, pois removem as relações sociais das imediações do contexto" (p. 36). Os sistemas peritos são "sistemas de excelência técnica ou competência profissional que organizam grandes áreas dos ambientes material e social em que vivemos hoje" (p. 35). Fichas simbólicas: "meios de intercâmbio que podem ser circulados sem ter em vista as características específicas dos indivíduos ou grupos que lidam com eles em qualquer conjuntura em particular" (p. 36). ** Desencaixe: "deslocamento das relações sociais de contextos locais de interação e sua reestruturação por meio de extensões indefinidas de tempo-espaço" (Giddens, 1991, p. 29).

Reencaixe: "meio de fixar confiança na confiabilidade e integridade de colegas" (p. 90).

*** "A reflexividade social diz respeito a uma sociedade em que as condições em que vivemos são cada vez mais o resultado de nossas próprias ações, e, inversamente, nossas ações vivem cada vez mais a administrar ou enfrentar os riscos e oportunidades que nós mesmos criamos" (Giddens, 2000, p. 20). 0 autor pode ter se utilizado do termo "relação de ref lexividade" da teoria dos conjuntos, que significa a propriedade entre elementos de um conjunto que é verdadeira quando relaciona um elemento consigo mesmo, empregando-o em
} analogia à ação transitiva de reflexão do sujeito. 


\section{Lígia Maria Moreira Dumont / Roberto Luís Capuruço $G$ attoni}

em novas práticas relativas ao trato com a informação. Parte-se do pressuposto de que a realidade dos sujeitos impulsiona e define as estratégias para a consecução das ações a serem empreendidas no seu cotidiano. Conseqüentemente, entre essas, en con tram-se as de busca de informações. Acredita-se que, se os contextos sociais não forem levados em suficiente consideração, as pesquisas e estudos em ciência da informação tornamse limitados, no mínimo distorcidos, no tocante às pesquisas do fenômeno informacional.

Isso posto, merecem destaque as observações de G iddens sobre a desorientação identificada nos indivíduos das organizações sociais nos dias atuais, como se esses tivessem sido apanhados em um universo de eventos que não compreendessem plenamente e que parecessem estar fora de seu controle. Os modos tradicionais de vida vêm-se transformando: "Sobre o plano extensional, novos fatores serviram para estabelecer formas de interconexão social que cobrem o globo; em termos intencionais, eles vieram a alterar algumas das mais íntimas e pessoais características de nossa existência cotidiana" (p. 14). Giddens, ao mencionar "modos tradicionais", referese às tradições, crenças e valores nos quais a sociedade se baseava para desenvolver suas ações sociais no período por ele mencionado como prémodernidade e modernidade. A coincidência tempo e espaço era a principal norteadora de ações nesse período. Já na alta-modernidade, a tradição foi substituída, perdendo então aquela referência tranqüila, certa e segura que a tradição, 'inquestionável', proporcionava e na qual os sujeitos se baseavam para desenvolver suas ações sociais.

Em decorrência da sensação de desconforto, ansiedade, ou mesmo de perigo ocasionada pela ruptura espaçotemporal e seu ritmo mais acelerado de mudanças - ou desencaixe -, os atores necessitam desenvolver ações que transmitam segurança para sobreviver. As pessoas não podem sentir-se em constante estado de risco; para ganhar segurança, desenvolvem, então, mecanismos de confiança nos sistemas peritos. G idden s exemplifica esse fenômeno, citando o caso da confiabilidade existente na tecnologia de fabricação de aviões e controle de vôos. 0 utro exemplo clássico que pode ser mencionado é a transformação do sistema bancário: de atendimento atualizado, nominal, para totalmente automatizado. Entretanto, mesclada à confiança encontra-se subjacente certa sensação de ansiedade, e este movimento oscilante, quase 'neurótico', que tende a ser camuflado, necessita ser neutralizado. Dessa maneira, os sujeitos de tempos em tempos aproximam-se de outras pessoas na ten tativa de amainar, apaziguar essa inquietação, ação esta denominada por Giddens mecanismo de reencaixe.
0 presente artigo versará sobre a nova terminologia e seus conceitos, que refletem o mundo mutante da modernidade estabelecida por Giddens. Procurar-se-á pontuar a discussão com exemplos do dia-a-dia referentes às interações exercidas por atores dos atuais cenários sociais, destacando-se as práticas informacionais desenvolvidas em intermediação com o computador, que foi, sem dúvida al guma, a tecnologia que mais progrediu e influenciou várias ações do cotidiano das pessoas. A proposta deste artigo refere-se a tentativas, inferências, ou mesmo exercício de aplicação, por analogia, dos conceitos referenciados aos sistemas de uso individuais. Trata-se, enfim, de ensaio que exemplifica novas ações cotidianas das pessoas no trato com a informação, percebidas ao longo da última década, centrando suas discussões, principalmente, no aporte teórico/social desenvolvido por Giddens. Visa também a contribuir para o debate em torno de questões relacionadas ao papel da informação na sociedade atual, pois acredita-se que a análise dos fenômenos apontados pelo autor podem acarretar melhor compreensão da complexidade da relação informação e sociedade.

\section{Sistemas abstratos: riscos e confiança}

A discussão sobre riscos na sociedade atual não é original de Giddens; já era encontrada na sociologia clássica. B eck (2000) cita, por exemplo, Ferdinand Tönnies e, posteriormente, Jürgen $H$ abermas \& Daniel Bell. Contudo, três sociólogos da contemporaneidade vêm tratando sistematicamente os conceitos de risco e ref lexividade na sociedade atual: Giddens, Beck* e Lash**. Advindos de linhas de trabalho diferentes,

\footnotetext{
* U Irich Beck explica a "modernização ref lexiva" como um fenômeno que, em virtude do seu inerente dinamismo, faz a sociedade moderna acabar com suas formações de classe, camadas sociais, ocupações, papéis dos sexos, família nuclear, agricultura, setores empresariais e também com os pré-requisitos e as formas contínuas do progresso técnico-econômico. Esse novo estágio, em que o progresso pode-se transformar em autodestruição, em que um tipo de modernização destrói outro e o modifica, é o que Beck denomina de "etapa da modernização reflexiva". "Em outras palavras, a modernização reflexiva também - e essencialmente - significa uma 'reforma da racionalidade' que faz justiça à ambivalência histórica a priori em uma modernidade que está abolindo suas próprias categorias de ordenação" (Giddens, A.; Beck, U .; Lash, S., 1997, p. 12).

** A partir do conceito de "sociedade da sensação" desenvolvido por Gerhard Schulze, Scott Lash elevou esta concepção à teoria da "reflexividade estética". 0 autor conecta a investigação aos limites da reflexividade, porque atribui a reflexividade estética à "razão emocional" prática. "A 'comunidade reflexiva' pode ser compreendida em relação ao conceito de 'campo' de Bourdieu. N esse caso, para Bourdieu, na sociedade tradicional não há campos, mas há comunidade. Entretanto, na modernidade há a diferenciação de vários campos 'delimitados' (religioso, político, legal, científico, artístico, acadêmico, sociológico) a partir dos quais surge o 'campo social' geral" (Giddens, A.; Beck, U .; Lash, S., 1997, p. 192)
} 


\section{As relações informacionais na sociedade reflexiva de $\mathbf{G}$ iddens}

convergem em vários temas. Primeiramente sobre a ref lexividade, que, embora por estes compreendida de maneiras diferentes, é tema dos mais importantes tratados pelos três pensadores. O utra convergência é o quase abandono à cansativa discussão sobre modernidade versus pós-modernidade. Em terceiro lugar, a noção de destradicionalização, cuja inovação conceitual refere-se a uma ordem social em que a tradição sofre ruptura no seu status. Ainda outra convergência temática refere-se à preocupação ecológica. Isso, afirmam, devido ao fato de o ambiente não se encontrar mais alheio à vida social humana. o que é "natural" está tão intrincadamente confundido com o que é "social", da mesma forma que muitos aspectos da vida eram governados pela tradição. A "natureza" transformou-se em áreas de ação nas quais os seres humanos têm de tomar decisões práticas e éticas.

N essas circunstâncias, ocorrem transições importantes na vida cotidiana, na intensificação da globalização e na tomada de decisões políticas. M erece destaque a automação, sem dúvida um dos maiores sistemas abstratos em que a sociedade da contemporaneidade se envolveu. Essa se encontra no dia-a-dia das pessoas, sendo até comum não perceberem a sua presença. Tida como a panacéia para vários problemas e fator inconteste para 0 desenvolvimento das sociedades, tal premissa agora se encontra relativizada. Por exemplo, a exigência de alto nível de padronização como prérequisito para a automação, relevando para segundo plano o fator humano, é argumento que não se sustenta mais. "A idéia de que uma simples dinâmica - a digitalização - é capaz de tran sformar a economia global em uma só direção e uma só meta pertence a premissas da primeira modernidade. Significa mais o risco entre escolher individualização ou pluralização" (Beck, 2000, p.72). 0 destaque à mudança de paradigmas é para reforçar a idéia de que a sociedade contemporânea está passando por período de transição, revolução de condutas e ações sociais.

Retornando à questão dos sistemas abstratos, acredita-se que, indubitavelmente, existem informações complexas - ou dados - impregnadas de conteúdos subjacentes às ações exercidas nas relações sociais e relações de trabalho. $\mathrm{N}$ a maioria das vezes, os atores envolvidos desconhecem essas informações, não se apercebem da sua existência, desconhecem quanta tecnologia e responsabilidade implicam. Tais realidades ou sistemas dão suporte ao fazer, à maneira particular de enxergar cada contexto. $\mathrm{E}$ simplesmente aceita-se que eles existam, confia-se cegamente que lá estejam desempenhando o papel que
Ihes cabe, mesmo que os indivíduos não entendam absolutamente nada sobre seus princípios de funcionamento.

Sobretudo no que tange à internalização ou não do perfil de risco que os sistemas abstratos impõem, Giddens (1993) verificou quatro reações de adaptação, ou absorção, realizadas pelos atores que interagem nesses cenários, as quais o autor classificou como "conseqüências da modernidade", a saber: a aceitação pragmática, 0 otimismo sustentado, o pessimismo cínico e 0 engajamento radical. Indubitavelmente, cada ator na sociedade requererá o tipo e as fontes de informação adequadas às especificidades da reação por ele desenvolvida.

Quanto à primeira - "aceitação pragmática" - cabe ilustrá-la por meio do empréstimo de famosa frase, expressa por Andrew G roove, CEO* da Intel**, na década de 90: "Só os paranóicos sobrevivem". Segundo o empresário, o sucesso atual no mercado de alta tecnologia de microprocessadores é efêmero, a não ser que haja compromisso constante com a in ovação tecnológica, perseguida "doentiamente" e de forma audaciosa. 0 executivo estabelece, com essa sentença, que 0 sucesso alcançado por qualquer indivíduo em determinada ocasião só é válido nesse momento, instantaneamente. A penas assim oferece ganhos. Groove vai além, afirmando que os resultados atingidos seriam considerados como meramente temporários; o minuto seguinte seria uma incógnita, tanto em termos de sucesso, quanto de fracasso. Essa instantaneidade levaria à formação de realidades e paradigmas momentâneos, equivalentes a frações de segundo. Tudo o que fosse planejado, mesmo obtendo resultados efetivos de sucesso, constituiria apenas ganho temporário. 0 fenômeno aceitação pragmática também pode ser exemplificado na prática dos mercados, na qual se observa a redução significativa do ciclo de vida dos produtos disponibilizados no mercado por diversos setores, bem como a nãofidelidade das pessoas a marcas e a empresas específicas. Assim, os indivíduos aceitam pragmaticamente essa realidade. De outra forma, há custos quanto à nãoaceitação dessas realidades, mesmo que brevemente estabelecidas. 0 risco e o custo de se incorrer em

\footnotetext{
* CEO - Chief Executive O fficer - expressão norte-americana cunhada para se referir ao executivo principal das organizações daquele país. ** A Intel é considerada uma das maiores fabricantes de microprocessadores de silício do planeta (com alto teor de certeza, este artigo não poderia ser produzido se não fossem os chips embutidos no computador de seus autores, que, aliás, é um "grande" e complexo sistema abstrato!)
} 


\section{Lígia Maria Moreira Dumont / Roberto Luís C apuruço Gattoni}

paradigmas ou situações momentâneas existiriam, mas os indivíduos são capazes de desenvolver métodos para bloqueá-los ou contorná-los internamente, de forma a sobreviver no dia-a-dia.

O utra reação de adaptação, o "otimismo sustentado" baseia-se sobretudo na argumentação racional e encontra respaldo no pensamento religioso. A tentativa de adaptação manifesta-se na procura de certezas, ações que respaldem as decisões das pessoas, que lhes transmitam segurança. Pode-se ilustrar tal tipo de reação quando sujeitos procuram respostas, 'consolo', em igrejas ou seitas espirituais alternativas, diferentes das normalmente aceitas: o esoterismo, ou ocultismo. São atitudes de sublimação da realidade, aliás muito bem sustentadas também pela indústria editorial. Ao elencar os itens das listas de livros mais vendidos confeccionadas por diversas agências de pesquisa, vários títulos dessa natureza encontram-se atualmente nos primeiros lugares de venda. Existe agora uma classificação especial para esse tipo de publicação denominada "livros de auto-ajuda". Anteriormente, esses se encontravam incluídos entre os livros classificados como "não-ficção".

Contrariamente, o "pessimismo cínico" decorre da premissa de que os fatos estejam caminhando para 0 lado não desejado, respaldando-se no cinismo como artifício de amortecimento das realidades em mudança, acredita-se, para pior. A reação é, pois, contrária à anterior, e, como exemplo, é possível citar alguns sujeitos que procuram a 'salvação' convertendo-se ao ateísmo. É comum também encontrarem força para sobreviver no âmbito familiar ou de trabalho, lançando manifestações declaradas de ceticismo, de negação de valores e crenças pela simples negação. Certamente em ambos os casos - no otimismo sustentado e no pessimismo cínico -, podem-se encontrar pessoas que assim agem porque acreditam em suas ações e os oportunistas, que vêem ali boa oportunidade de tirar proveito para si próprio. Valem-se da insegurança dos sujeitos que se encontram desenvolvendo mecanismos de sobrevivência e, portanto, de certa forma, fragilizados e vulneráveis para praticar atividades que Ihes dêem lucro, poder ou até mesmo autoestima.

Por fim, o "en gajamento radical", a última forma de reação de adaptação citada por Giddens, refere-se a qualquer movimento, até certo ponto otimista, no sentido de contestar as realidades atuais e acreditar que a mobilização para superar ou transcender as dificuldades traria melhorias. No entanto, não imprime racionalidade às decisões e discussões; enfatiza a crítica da realidade e a contestação via movimento social. Historicamente, a
I greja Cristã tem praticado e divulgado entre seus fiéis esse tipo de atitude. No entanto, sabe-se que ensinamentos impostos, por mais que se pressionem os sujeitos, não implicam a total absorção dos mesmos como repassados, devido à subjetividade desses sujeitos. V erificase muitas vezes que é a opção do sujeito por ações alternativas, tomadas de acordo com a sua realidade, a sua vivência. Essas ações podem acarretar resignação apática, ou, como destacado por Giddens, en gajamento radical. C onvertem-se em atitudes de grande exaltação. Exacerbadas, tais reações tornam-se altamente perigosas, pois o sujeito mostra-se excessivamente faccioso, fanático. As manifestações terroristas enquadram-se nessa classificação. As informações demandadas por esses atores advêm praticamente de poucas e similares fontes de informação.

Propondo mudanças drásticas quanto aos papéis sociais desempenhados na sociedade, Giddens oferece dois enfoques principais. 0 primeiro seria que "o indivíduo passa a ser aceito como é", ao contrário da abordagem existente em época anterior que preconizava "a sociedade molda o indivíduo". Em outras palavras, cada indivíduo seria um 'sistema abstrato', e a sociedade nem sempre seria capaz de determinar suas ações ou forma de ser. Suas reações estariam além da capacidade de entendimento e previsão, uma vez que seriam regidas pelo seu eu, do qual a sociedade necessariamente não possuiria controle ou conhecimento; seria a subjetividade dos atores sociais posta em cena.

0 segundo enfoque seria a oferta de "novo paradigma relativo à ciência", pois esta, segundo o autor, não soluciona todos os problemas da sociedade. Há outras alternativas, principalmente as de origem comunitária. D essa forma, estaria Giddens a propor a "terceira via de desenvolvimento sustentado", nem tão liberal, nem tão marxista.

\section{DESLOCAMENTO E REENCAIXE}

A partir do exposto, podem-se exemplificar os mecanismos de segurança que os atores sociais desenvolvem nos sistemas peritos no seu dia-a-dia. É possível discorrer sobre alguns flagrantes da realidade física convencional e sobre aquelas que 0 universo virtual - fixando em um dos sistemas abstratos contemporâneos - passa a representar, ou exacerbar, ou até mesmo substituir, que vêm modifican do o fazer diário das pessoas. U ma verdadeira revolução de comportamento que, pouco a pouco, tende a determinar importantes transformações naquilo que hoje se conhece como vida urbana. U m cotidiano cada vez mais independente dos compromissos 


\section{As relações informacionais na sociedade reflexiva de $\mathbf{G}$ iddens}

de horário ou do deslocamento das pessoas, que propõe instigante ruptura com as velhas noções de espaço/ tempo impostas pela Revolução Industrial e que marcou a organização social do mundo ocidental, principalmente a partir da segunda metade do século XIX.

A lgumas manifestações curiosas estão surgindo e ilustram bem as novidades contemporâneas concernentes às interações sociais cotidianas. Para iniciar, pode-se citar bem a propósito o exemplo da imensa quantidade de adolescentes que ingressam na Internet para praticar "interações telemáticas". A rede está progressivamente arregimentan do mais e mais pessoas para 0 mundo virtual, "que apresentam alguns comportamentos patológicos similares aos adolescentes das sociedades fisicamenteinstituídas" (Bretas, 2000). Aliás, nem poderia deixar de acontecer de outra forma, uma vez que ainda se trata de seres humanos. $E$, ainda assim, por mais estranho que possa parecer em relação aos métodos tidos como "tradicionais" antes exercidos, continuam namorando, travando batal has em jogos por computador, consultando 0 analista e debatendo assuntos que sempre os atormentam na adolescência, como relacionamento sexual, problemas com a família, a escola, drogas, ou conversando sobremúsica, esportes, trabalho elazer. M as, o curioso é que os meios empregados para as interações entre eles estão em esfera eletrônica, virtual, ou seja, não existem fisicamente.

No plano organizacional, a mídia divulgou no início de 2000 um dos mais impactantes casos de ataque eletrônico, em que diversas e significativas empresas americanas ficaram com seus sites não disponíveis na Internet, devido à sobrecarga de informações que impediam 0 acesso a seus serviços. Tais ataques, presumiase, haviam sido produzidos por piratas eletrônicos, ou hackers, externos às organizações. Controvertidamente e à mesma época, estudos desenvolvidos pelo $\mathrm{G}$ artner Group* revelaram que cerca de $80 \%$ dos problemas relativos à insegurança das informações corporativas são originados por pessoas que operam no próprio interior das empresas. Devido a essa nova realidade, presupõese que a internet não estaria agindo como potencializador de vulnerabilidades; as pessoas é que encontram possibilidades e oportunidades de iniciativas criminosas e mal-intencionadas, da mesma forma que encontravam nos sistemas de segurança anteriores. Constata-se, portanto, que estas não são as principais questões que tornam as corporações mais acessíveis a ataques malintencionados; independem se tais ameaças advêm do

\footnotetext{
* Gartner Group - organismo de pesquisa norte-americano especializado na área de tecnologia da informação.
}

ambiente externo ou interno, alavancadas ou não por maior oferta de meios eletrônicos.

O utro exemplo refere-se ao fato de as pessoas comumente possuírem o hábito de guardar símbolos, objetos que evocam determinado momento. São ações que de alguma forma concretizam determinadas lembranças, vivenciadas por sujeitos nos seus círculos sociais, entre parentes ou amigos. Sem querer remontar a fatos nostálgicos ou demonstrar traços de saudosismo, podese citar como exemplos caixa de lembranças com bilhetinhos, fotografias e filmes, o primeiro presente dado pelos pais... Esses são, em geral, fortes símbolos de momentos, de épocas, de lembranças de vida; representam a prova da existência daquele momento, e 0 ato de guardá-los anos após terem sido utilizados traz a comprovação do valor simbólico intrínseco. No espaço virtual, como estabelecer ícones que possuem o mesmo significado? A questão-chave reside em quais seriam os sistemas abstratos 'psicológicos', ou 'afetivos', que os atores estariam a guardar, a partir do momento em que passem a navegar pela internet. Cartões de aniversário virtuais? 0 u mesmo flores virtuais? $\mathrm{U}$ m email parabenizando pelo sucesso em algum empreendimento? Certamente os sujeitos que navegam pela internet estão encontrando formas de desenvolver essa necessidade de registrar momentos da sua história de vida nas comunicações, nas suas interações telemáticas.

Dentre as novidades apresentadas nas grandes metrópoles, como o aumento dos problemas de violência, criminalidade, tráfego urbano, distâncias, poluição e outras singularidades, como 0 crescimento da faixa etária da população acima de 60 anos nos países desenvol vidos, os indivíduos estariam caminhando para uma sociedade baseada na troca de informações e mensagens, com pouca ou nenhuma interação entre indivíduos de 'carne e osso'? Existem sites de batepapo que possuem salas distribuídas por assunto, podendo os participantes escolher explicitamente com quem conversar e com quem não conversar. Encontram-se disponíveis lojas virtuais e supermercados onde a visita às gôndolas e a escolha de produtos são realizadas amplamente pelo usuário e 0 pagamento feito via débito em conta, ou por meio de cartão de crédito; as compras podem ser recebidas na portaria de um edifício, diretamente pelo porteiro do prédio onde se mora. É possível conhecer e adquirir as principais obras literárias recém-elaboradas sem ser preciso ir à livraria, visitar todos os principais museus do mundo em uma ou duas tardes, gravar CD convencional com 200 músicas, selecionadas dentre diversos cantores, conjuntos ou orquestras, sem a necessidade de adquirir todos os CDs e gravar uma ou 


\section{Lígia Maria Moreira Dumont / Roberto Luís Capuruço $G$ attoni}

duas faixas de cada um. Tornou-se economicamente viável participar de um curso de pós-graduação pela videoconferência, comunicar-se com os orientadores por email e receber os trabalhos finais pelo mesmo meio; receber o resultado da avaliação da banca examinadora 'afixado' na homepage da instituição de ensino. Tudo isso com pouco ou quase nenhum esforço de deslocamento, ao alcance de alguns cliques de mouse e contas a pagar à companhia telefônica, em contato direto com as nuances do ciberespaço sem fronteiras.

A presentando vantagens absolutas apontadas por alguns teóricos, a realidade do dia-a-dia pode às vezes demonstrar outras conseqüências. U ma verdadeira façanha a ser comemorada, não fosse um detalhe: apenas uma ínfima parcela da população tem acesso a essa "revolução", que, no Brasil, ainda não superou a marca de 5 milhões de indivíduos conectados à I nternet por seus próprios meios. Sem dúvida, a sociedade contemporânea convive com enorme teia de informações, de saberes científicos aplicados, mas torna-se importante ressaltar que nem todos os segmentos sociais usufruem essas possibilidades, criando-se assim enorme fosso entre estes e os que possuem, ou têm acesso ao equipamento necessário ao seu uso.

Contudo, a troca de informações entre colegas, o contato presencial e a descoberta dos seus sistemas abstratos individuais englobados pelas facilidades da 'escolha virtual' são necessidades de que os usuários - a princípio compulsivos - dessas novas formas de interações sociais vêm-se ressentindo ultimamente. Algumas instituições, como os estabelecimentos bancários, estão voltando ao tradicional contado do gerente com os correntistas. Além das reclamações dos clientes, os ban cos certamente constataram diminuição nos investimentos financeiros oferecidos.

A penas como ilustração, é possível também traçar paralelo entre os sistemas peritos tratados por Giddens e 0 enorme banco de dados virtual, a Internet. Pierre Lévy demonstra especial gosto pelo tratamento do imenso sistema abstrato de informações, por ele denominado "ciberespaço". Talvez a realidade imaginária mais "fisicamente" representada em todos os tempos, esse grande universo virtual e eletronicamente conectado, ofereça portais não somente a todo e qualquer tipo de informação, mas também possibilite o desbravamento das fronteiras do entretenimento e da estética, dentre outros e, sobretudo, potencialize as possibilidades de relacionamento do indivíduo como ser social (mesmo que 'virtualmente' considerado), conforme explica Lévy.
Torna-se evidente, porém, que 0 aumento do bemestar social e 0 aumento dos riscos condicionam mutuamente um ao outro. À medida que isso se torna público, os defensores da segurança não se encontram do mesmo lado político que os produtores de riqueza econômica. A tecn ol ogia facilita a vida das pessoas em vários aspectos, mas pode também criar diferenças e ilegitimidades. $\mathrm{Na}$ realidade, sancionam-se - ou tenta-se sancionar - as desvantagens juntamente com as ameaças, ou seja, acionase 0 mecanismo denominado por Giddens adaptação aos riscos dos sistemas abstratos, descritos anteriormente. É indubitável que esses sistemas revertem-se principalmente em ganho de tempo, conforto e agilidade nas ações do dia-a-dia, sem entrar em detalhes das muitas outras vantagens observáveis nos setores tecnológico, econômico e de administração de informações estratégicas, entre outras. Por outro lado, também se verificam problemas decorrentes dessa nova realidade. Como exemplos, logicamente aliados ao modelo capitalista vigente na maioria das sociedades contemporâneas, podem-se citar as perdas no mundo do trabalho, que na atualidade passa por crises e mudanças substanciais, 0 acesso à informação cada vez mais distante dos que não possuem as tecnologias de informação e de comunicação e a exclusão dos jovens advindos dos estratos sociais mais carentes em estabelecimentos de ensino equipados com estas tecnologias.

\section{CONSIDERAÇ ÕES FINAIS}

Acredita-se que os exemplos ilustram algumas "transformações da intimidade" ocasionadas pela atualidade, que são as mudanças das ações dos atores no seu cotidiano, pontuadas por algumas novas formas e estratégias de busca e de uso das informações. As regras e tecnologias relativas à operacionalização dos sistemas abstratos, premissas e princípios aceitos e largamente implementados e otimizados pelos diversos atores envolvidos em sua arquitetura efetivam-se principalmente pela "existência virtual" do ciberespaço. Esse é in exoravelmente aceito como fato, como verdade, como sistema abstrato completo, porém, paradoxalmente, inacabado, sendo que a interação dos atores no mesmo encarrega-se de reconstruí-lo a todo o tempo.

Calvino (1990), em sua última e inacabada obra Seis propostas para o próximo milênio, destaca leveza, rapidez, exatidão, visibilidade, multiplicidade e consistência como parâmetros norteadores das obras literárias vindouras. Talvez, ao propor tais atributos, poderia estar o escritor especulando, ou estabelecendo, quais seriam os pilares do sistema abstrato subjacentes à consciência crítica e 


\section{As relações informacionais na sociedade reflexiva de $\mathbf{G}$ iddens}

literária do final do século XX. O rientados por esses balizadores, mesmo sem a percepção consciente do fato, os escritores, poetas, dramaturgos, novelistas, contistas e romancistas, ou mesmo jornalistas, articulistas, editores, professores, cientistas e tantos outros envolvidos na elaboração de conteúdos estariam seguindo os moldes de um sistema perito que não se ateria apenas a aspectos literários. Em princípio, esses atributos encaixam-se perfeitamente nos designados pelos apologistas das novas tecnologias.

As questões e indagações propostas neste artigo não possuem ainda explicação precisa e, acredita-se, nem necessitam. São identificadas como novas formas de ação social que se apresentaram à sociedade muito recentemente; surgiram e continuam chegando velozmente, de forma impactante e talvez de maneira inexorável e sem retorno. Q uando a sociedade começa a assimilar al guns fatos ou ações, estes já podem até estarse tornando ultrapassados. As ameaças e riscos são especulativos, pois ainda há controvérsias quanto aos efeitos ocasionados pelas novas tecnologias. A informação sobre novos feitos surge em ritmo vertiginoso, sua utilização pode até se tornar comum e em larga escala antes mesmo de os cientistas iniciarem suas investigações sobre o impacto que porventura esta possa causar.

Tais realidades têm ocasionado outros exemplos de ações, destacados por Giddens em duas de suas publicações (Giddens, A.; Beck, U.; Lash, S., 1997 e Giddens, A.; Pierson, C. 2000). $\mathrm{N}$ a realidade, trata-se da coleta de alguns papers, entrevistas, diálogos, réplicas e tréplicas entre autores, mas chama a atenção determinado assunto abordado dentre outros temas, quando Giddens destaca um novo fenômeno da contemporaneidade, 0 fundamentalismo. Explica que se trata da reação exarcebada de al gumas religiões que se sentem inseguras devido à quebra de tradições e às novidades trazidas pelo mundo cosmopolita. Giddens explica que as tradições sofrem modificações, ou adaptações, na contemporaneidade, por meio de processo dialógico. U ma defesa discursiva da tradição necessariamente não compromete a "verdade formular". A o contrário, a tradição se transforma em fundamentalismo. Porém, 0 autor não considera que o fundamentalismo signifique "retorno ao passado" ou "uma insistência em relação aos princípios básicos". 0 fundamentalismo pode ser compreendido como uma asserção da verdade formular sem levar em conta as conseqüências. E prossegue:

"Sempre que algo usualmente determinado pela 'natureza' - seja ela o ambiente ou a tradição - torna-se uma questão de tomada de decisão, novos espaços éticos são abertos e novas perplexidades políticas são criadas. $N$ esses espaços, as tensões entre o diálogo e a afirmação da certeza moral freqüentemente tornam-se intensas. Os fundamentalismos podem surgir em todas as arenas abertas pela transformação da natureza e da tradição [...] Podemos falar nesse sentido, não somente do fundamentalismo religioso, mas também - entre outros - de fundamentalismos do nacionalismo, da etnicidade, da família e do sexo [...] na medida em que cultivam os terrores que a diferença em todas as suas formas pode inspirar, os fun damental istas tornam-se perigosos. N esse aspecto, o fundamental ismo é mais que apen as uma recusa ao diálogo, ele transforma em demônio o estranho" (Giddens, A .; Beck, U .; Lash, S., 1997, p. 225-226).

Ressalta-se, contudo, que Giddens contrabalança essa afirmativa, lembrando que os extremistas necessitam ser ouvidos. $\mathrm{N}$ ão se pode chegar à conclusão perversa de que, na contemporaneidade, a conservação das tradições e a criação de valores éticos não são ações "corretas", não podem ser explicadas pelo contexto histórico dos seus defensores. Sem dúvida, essa é mais uma manifestação social a ser considerada como qualquer outro tipo de ação advinda de grupos socialmente constituídos.

Complementa, estabelecendo que tal extremismo prendese à insistência em se afirmar que somente é possível uma visão do mundo e que eles já possuem essa visão. Recusam qualquer diálogo, não permitem que informações circulem pelos integrantes do segmento e terminam por radicalizar suas idéias. V erifica-se então 0 fenômeno da contemporaneidade identificado pelo autor como "reflexividade", que ocasiona ações do tipo presenciadas pelo mundo, quando do ataque às torres gêmeas em N ova Y ork. A atual realidade social e mundial, em que as interações sociais se efetivam conforme a historicidade, contexto e subjetividade de seus atores, encaixa-se perfeitamente na referência de Giddens, "vivese hoje em uma sociedade de riscos". Resta agora aguardar os desdobramentos que advirão em decorrência do 11 de setembro, já considerado como um marco de reviravoltas na história mundial. Talvez 0 mundo ocidental - e sua vontade globalizante - perceba que esses novos cenários apontam para a necessidade de melhor se refletir sobre o relacionamento com as sociedades em que tradição, política e religiosidade se amalgam em um só movimento. 


\section{Lígia Maria Moreira Dumont / Roberto Luís Capuruço Gattoni}

Para finalizar, acredita-se que a compreensão dos fenômenos informacionais dá-se, necessariamente, pela observação da sociedade e das práticas de circulação das informações naquele dado contexto, análise esta centrada nas redes socioculturais, nas quais se consolidam opiniões, crenças e ações. 0 desafio consiste, então, em saber sintonizar as teorias e práticas sociais com as ações informacionais, para que se possa apreender, com 0 mínimo de distorções, o fazer e o uso de informações nas sociedades contemporâneas.

\section{REFERÊNCIAS}

BECK, U Irich. The risk regime: how the work society is becoming risk society. In: The brave new world of work. Cambridge, UK : Polity Press, 2000. C. 5, p. 67-91.

BRETAS, M aria Beatriz Almeida Sathler. Interações telemáticas: estudo sobre jovens internautas de Belo Horizonte. 2000. Tese (D outorado) - Escola de Ciência da Informação da U FM G, Belo H orizonte, 2000.

CALVIN O, Ítalo. Seis propostas para o próximo milênio. São Paulo: Companhia das Letras, 1990.

GIDDENS, Anthony. As conseqüências da modernidade. São Paulo : UNESP, 1991.

A transformação da intimidade. São Paulo : U nesp, 1993.

; BECK, U Irich; LASH, Scott. M odernização reflexiva: política, tradição e estética na ordem social moderna. São Paulo : U nesp, 1997._._._. PIERSON, Christopher. Conversas com Anthony Giddens. Rio de Janeiro : FGV, 2000.

LÉVY, Pierre. As tecnologias da inteligência; o futuro do pensamento na era da informática. São Paulo : Editora 34, 1995. 